Boise State University

ScholarWorks

Communication Faculty Publications and

Presentations

Department of Communication

6-1-2015

\title{
Media Literacy in Action?: What Are We Teaching in Introductory College Media Studies Courses?
}

Seth Ashley

Boise State University 
This is an author-produced, peer-reviewed version of this article. The final, definitive version of this document can be found online at Journalism \& Mass Communication Educator, published by SAGE. Copyright restrictions may apply. doi: 10.1177/1077695815572191

\title{
Media Literacy in Action?: What Are We Teaching in Introductory College Media Studies Courses?
}

\author{
Seth Ashley \\ Boise State University
}

\begin{abstract}
An introductory media studies course is a staple of post-secondary education. What are instructors teaching in this course, and to what extent are the principles of media literacy education being incorporated into this likely home? This article reports the findings of a small survey of instructors, who describe aspects of their course content and pedagogy. Media literacy appears to provide a basic foundation in most cases, though instructors struggle with structural constraints. Findings suggest that more focus should be placed on teaching the political and economic contexts of media, and that instructors should embrace active learning and creative engagement.
\end{abstract}

Some variety of an introductory media studies course is a staple of post-secondary education in the United States. Journalism and mass communication programs commonly offer such a course to introduce students to media theory and criticism, and to learn the basics of media industry operations. Students within mass communication programs often take such a class before they advance to hands-on, skills-oriented classes and upper-level theory courses. Nonmajors take such a class to meet general education requirements and to learn to navigate the media landscape. Thus, the introductory course is the ideal place to introduce a wide array of students to the principles of media literacy education. But what is the focus of these introductory courses, and to what extent are the principles of media literacy education being incorporated into this likely home? As there is no agreed-upon canon of introductory media studies, this article centers on an analysis of literature and a small survey of instructors to see what is commonly included in an introductory media studies class and to establish best practices for programs and instructors trying to modify or create such courses.

This study is motivated by the growth of media literacy education over the past few decades concurrent with the explosion of media platforms and constantly connected citizens thanks to digital technology (Hobbs, 2010, 2011a). Volumes have now been written about the need for digital and media literacy, and researchers have addressed a range of questions related to pedagogical and assessment challenges. Less is known, however, about exactly whether and how the principles of media literacy are being integrated into college classrooms. We tend to assume that media instructors, through some combination of experience and expertise, know what to teach and how to teach it, but no analysis exists of the actual pedagogy and content of college-level introductory media studies courses.

This study looks specifically at the introductory media studies course because it is pervasive and a likely home for the integration of media literacy education. In this context, a range of questions can be raised: What do we expect students to know and be able to do after this introductory course? What content areas do such courses typically include? What texts are commonly used? What assessment mechanisms are common? To what extent do instructors incorporate active learning techniques versus traditional lecture formats? Most importantly, what impact do we hope to have on students' lives? How can we engender critical awareness and thoughtful citizenship without inducing cynicism or apathy? In this context, this article aims to contribute to the definition and deployment of media literacy, and to help establish common goals for undergraduate media literacy education. 


\section{Literature Review}

Why Media Literacy?

Media education has a long history but has received new attention since the 1990s. The field of media literacy has grown and taken on newfound relevance as media messages and distribution channels have become increasingly pervasive (Hobbs and Jensen, 2009). The basic definition - the ability to access, analyze, evaluate and communicate a variety of media messages (Aufderheide, 1993) —has taken a range of forms, but the principles have remained consistent. Generally, media literacy education aims to make media consumers aware of their media environments and increase critical thinking about media representations (Silverblatt, 2008; Hobbs, 2011b). Media literacy helps audiences become aware of how media depict and reflect a socially constructed reality and also helps audiences understand that these depictions and reflections are subject to a variety of influences that often serve a limited set of interests (See McChesney, 2004; Shoemaker \& Reese, 2013). In the media-saturated cultures of the Western world, a lack of media literacy may present a danger to society if individuals are not properly equipped to evaluate and analyze the endless stream of media messages they receive.

Beyond this general approach, scholars have debated exactly what it means to be media literate (Christ and Potter, 1998; Potter, 2010; Hobbs, 2011b). A lack of consensus has led to some disagreement when it comes to implementing media literacy education in America's schools and colleges. As Christ noted in 2004, "Recent assessment trends suggest that those interested in media literacy in higher education will need to clearly define the term and develop standards and competencies to measure media literacy student-learning outcomes" (Christ, 2004, p. 92). This remains a work in progress.

\section{Defining and Assessing Media Literacy}

Researchers have noted that much of the scholarly attention has been paid to the role of media literacy in K-12 education (Christ \& Potter, 1998; Dennis, 2004), while media education at the college level is more likely to be viewed in terms of professional orientation and job training (Christ \& Hynes, 1997). But as Christ and Potter note, "many of the questions asked in the media literacy debates have direct application to higher education. For those in higher education, the process of defining media literacy requires teachers and scholars to take a hard look at what and how they teach" (1998, p. 8).

In one approach, Potter's cognitive model of media literacy (2004) emphasizes "conscious processing of information" and "preparation for exposures" (p.68) by focusing on five knowledge structures, including media effects, content and industries as well as personal motivations and feelings of control. According to Potter, with these knowledge structures, "people are much more aware during the information-processing tasks and are, therefore, more able to make better decisions about seeking out information, working with that information, and constructing meaning from it that will be useful to serve their own goals” (p.69). Alternatively, Hobbs (2011b) tends to stress the importance of inquiry as the correct path to engagement rather than the mere transmission of knowledge:

Too many college faculty view media literacy as simply a watered-down version of the standard content-based Media and Society course for non-majors, and this view does considerable disservice to the field. At the heart of digital and media literacy, education is not the mere transmission of facts and information about media industries, audiences and effects, but the goal of promoting a deep understanding of the concept of constructedness (Hobbs, 2011b, p. 427).

Scholars have also argued that the goal of media literacy is to help people become sophisticated citizens by analyzing the political and economic structures of media institutions (Lewis \& Jhally, 1998; Kellner and Share, 2005). Masterman (1997) writes that media education will inevitably lead to improved citizenship and social change, and Ewen (1996) agrees that media literacy should be viewed as "an education in techniques that can democratize the realm of public expression and will magnify the possibility of meaningful public interactions” (p. 414). Thus, there is some tension between those who advocate for a critical approach, those who focus on specific knowledge structures and those who prefer to focus on the process of inquiry. 
This is an author-produced, peer-reviewed version of this article. The final, definitive version of this document can be found online at Journalism \& Mass Communication Educator, published by SAGE. Copyright restrictions may apply. doi: 10.1177/1077695815572191

The broad range of approaches to media literacy speaks to competing notions of proper implementation (Potter, 2010), but a growing number of studies demonstrate a variety of positive effects of media literacy education in its many forms. One meta-analysis of 51 studies of structured media literacy programs found such interventions to be successful in increasing critical awareness of the media landscape and reducing negative or risky behaviors or beliefs (Jeong, Cho and Hwang, 2012). Two recent studies in Journalism and Mass Communication Educator focused on news found similar results: An analysis of one news literacy program found that undergraduates were receptive to a general education approach to learning about news media (Fleming, 2014), and another study, calling for greater attention to the political and economic contexts of news media, found that media industry knowledge correlates with current events knowledge (Ashley, Maksl and Craft, 2013).

Despite the growing body of evidence, challenges remain in teaching and research. Hobbs (2011a) has called for a focus on learning outcomes and transfer of learning beyond the classroom:

We are now learning a lot about the experiences that some children and young people are having using digital media, living their lives online. But it will require a range of research methodologies to discover why, for some students, such activity seems to naturally promote critical consciousness and for others it’s just another form of inconsequential diversion (Hobbs, 2011a, p. 30).

Overall, media literacy is an increasingly important component of education at a variety of age levels, and given what we know, we would expect its fundamental principles to appear in a college-level introduction to media or mass communication course. Thus, this study seeks to address the following research questions:

RQ1: What are the common characteristics of the content and pedagogy of introductory media studies courses?

RQ2: How are principles of media literacy education being integrated into introductory media studies courses?

\section{Method}

To address these questions, a survey was designed with a range of quantitative and qualitative items. The survey was constructed and deployed using Qualtrics. After obtaining IRB approval, a database of email addresses for program chairs and administrators was obtained from the program directory of the Association for Education in Journalism and Mass Communication. This included accredited and non-accredited programs in journalism and mass communication. Using Microsoft Excel, a randomized collection of 200 email addresses was assembled. Many of these addresses were apparently out of date, as 70 of them generated automated undeliverable replies. Three individuals wrote back to say they were retired or did not offer a relevant course. That left 127 successful email contacts, though some were surely lost as spam or otherwise ignored. These successful contacts were asked to invite instructors who teach Introduction to Media or a similar introductory media or mass communication course to take a short survey, and an anonymous link was included. This resulted in 33 fully completed surveys for a response rate of 26 percent. This response rate can be expected with a mass-emailed survey request. This sample of respondents, though small, provides a starting point for describing and understanding the introductory media course, and it made for a manageable number of responses to the open-ended, qualitative questions in the survey (See Appendix A).

\section{Findings}

The introductory media studies course must fulfill many functions and meet multiple needs. It must entice majors and non-majors alike, it must prepare students for future study in media theory and practice, and it must cover a large amount of material in a field that is undergoing massive changes. Instructors must balance the need to convey specific content area knowledge with the need to stimulate critical inquiry and original analysis. A review of common characteristics of the introductory course reveals the tension between these domains. 
This is an author-produced, peer-reviewed version of this article. The final, definitive version of this document can be found online at Journalism \& Mass Communication Educator, published by SAGE. Copyright restrictions may apply. doi: 10.1177/1077695815572191

\section{Course Title, Enrollment and Other Basics}

"Introduction to Mass Media" was the most commonly reported course title, followed by "Living in a Media World," "Media and Society," and "Introduction to Mass Communication.” Enrollment ranged from 16 students to 380 students, with an average of 72 . All but one respondent reported that their course is required for majors, yet all but three of the classes contained both majors and non-majors. Twenty respondents said they alone control the content of their course, while 13 collaborate with others to design their course. Years of experience teaching the course ranged from one to 37 , with an average of 7.2.

\section{Course Content}

Asked for the title of their primary text, 17 respondents reporting using one of the many popular introductory textbooks. Seven respondents reported using "Media and Culture" or "Media Essentials" by Richard Campbell and colleagues, the most common selections. Other reported introductory media texts included John Vivian's "The Media of Mass Communication,” Joseph Turow’s “Media Today,” Shirley Biagi’s “Media Impact,” Ralph Hansen’s "Living in a Media World," Stanley Baran's "Introduction to Mass Communication," and "Media Now" by Joseph Straubhaar and colleagues. Three respondents reported using no text but instead assign articles. Four respondents reported using a text oriented toward media or journalism practice, such as "Writing for the Mass Media" by James Glen Stovall and “Telling the Story” by The Missouri Group.

Respondents were asked what they cover in their course and were asked to select all that apply from a list of content areas (Table 1). Most respondents selected multiple options, the most popular being media history, media ethics, media industries, media literacy, media effects and critical thinking, all selected by at least 75 percent of respondents. "Other" responses included media law and regulation, media content and English grammar and writing skills.

[Table 1 here]

Respondents also were asked which of the content areas they would choose if they had to pick a primary focus (Table 2). Media literacy was most common, followed by media industries, concepts and theories, and media skills/production. “Other” responses included digital media and “I wouldn’t pick one.”

[Table 2 here]

\section{Assessment Tools}

Respondents were asked to report which assessment tools they use (Table 3). Papers, essay tests, quizzes and inclass exercises were most common, with at least half reporting using these tools. "Other" responses included online assignments, published news work, student media participation and a multi-part journal.

[Table 3 here]

\section{Class Time}

Respondents were asked to report how they use class time in a typical week, applying a percentage to each of a range of activities for a total of 100 (Table 4). Lecture was used by all to some degree, but ranged from 10 percent of class time to 96 percent with an average of 52 .

[Table 4 here]

\section{Choosing Course Content}

The first open-ended question-How do you decide what to cover in your course? — garnered a wide range of responses. Respondents commonly said they rely on their own professional experience and background, as well as their knowledge of current industry trends. Several reported following a textbook and emphasizing areas they deem most important or interesting. For example: "I pick what is most interesting to me or what is most vital for the 
This is an author-produced, peer-reviewed version of this article. The final, definitive version of this document can be found online at Journalism \& Mass Communication Educator, published by SAGE. Copyright restrictions may apply. doi: 10.1177/1077695815572191

students to know from each chapter. Each chapter gets a day and a half, approximately 3 hours.” One respondent referred to AEJMC standards, and a few said they rely on input from other faculty. One referred to course goals, noting that: "Course goals determine the content. Simply put, I ask students to address two overarching themes of critical consumption of the media and responsible production -- what those concepts mean and how to enact them.”

\section{Obstacles to Achieving Learning Goals}

What obstacles do you face in achieving your learning goals in this course? Respondents commonly mentioned structural obstacles such as class size, limited time, teaching online, and teaching to a mix of majors and non-majors. Respondents also commonly noted that students are not as engaged as the instructor would like, do not buy or do not read the assigned text, do not work hard enough, do not turn work in on time or are easily distracted. One respondent noted the difficulty of teaching to a wide range of abilities: "I have just a few students with exceptional talent, a very wide delta and then everyone else. So 'teaching to the top' leaves too many people behind - I find it's not useful for engagement. So finding the right level for a majority - while not short-changing the top - is a huge challenge.” Another respondent highlighted the difficulty of engaging first- and second-year students in a lecture format: "The main challenges have to do with student maturity and level of engagement. This is a large class of mostly freshmen and sophomores, hardly an ideal group for lectures. I am working to lecture as little as possible, because I don't find it the most effective way to educate this group. They respond much better when given opportunities for engagement. There is always room for improvement in lecturing, but I don't think these younger students consistently respond well to even a talented lecturer."

\section{Influence of Pedagogical Research on Teaching}

How does research related to pedagogy influence your teaching? Six respondents replied "very little," "minimally," or "not much." Eight respondents indicated some reliance on research to inform teaching. Those respondents commonly noted that they work to reduce their amount of lecturing, develop class exercises and improve interactivity. For example: 'I try not to simply lecture, ever. I try to always use 'flip the classroom' techniques by having students watch videos outside of class so we can discuss them in class; by framing lectures as more of a discussion, with lots of examples and easy-to-answer questions to build confidence among students to speak in class, and use of the Clicker technology." Another respondent noted a reliance on peer instructors: "I constantly study what other faculty are using as methods and approaches to topics I am teaching. I also study trends in those approaches through research in teaching effects. I seek to apply learning theories to my teaching each semester.”

\section{Fostering Engagement}

Does your approach encourage engagement with media and civic life? If so, how?

Nearly all respondents said “yes." Several reported that they emphasize current events and media's role in democracy, and that students are encouraged to become critical consumers and to see how media directly affects them. One noted: "I urge students to learn media consumption skills for traditional newspapers, online media, and digital/interactive media. I also point out the intersections of media and public discourse, political life in our nation (at local, state and national levels), and point out the ways journalism is uniquely suited to democracy; I point out that democracy, as an experiment, depends for its vibrancy on robust journalistic functioning in society.” Most respondents reported that their students are required to consume and analyze a variety of media each week. Two respondents said their course requires students to work at a student media outlet.

\section{Managing Diverse Perspectives}

How do you attempt to manage diverse perspectives in the classroom (race, class, gender, political views, etc.)? Respondents generally noted that they teach respect for each other's opinions, encourage open discussion, and embrace multiple viewpoints. One instructor wrote: "At the outset, I talk about the need for an open and tolerant class environment, and I remind them of this if/when conversation gets heated. I try to control the conversation as little as possible when it is divisive, but then to contextualize and refine once opinions have been articulated. I preach a lot about the benefits of transparency." Another instructor focused on the range of voices available: "I emphasize the importance of minority voices, the dangers of majority culture's myopia as regards minority cultures, and I urge students to come at the news in a holistic way - seeking out all voices as a means of getting at the truth.” 
This is an author-produced, peer-reviewed version of this article. The final, definitive version of this document can be found online at Journalism \& Mass Communication Educator, published by SAGE. Copyright restrictions may apply. doi: 10.1177/1077695815572191

\section{Discussion}

The introductory media studies course offered through programs of journalism and mass communication appears to be rooted in many of the principles of media literacy education, and many instructors appear to be attempting to accomplish a great deal when it comes to covering a broad range of content and skills in the limited time of a single academic term. Notably, 83\% included media literacy as part of their course content and 23\% said it is their primary focus. The findings above help to answer the first research question regarding the common characteristics of the content and pedagogy of introductory media courses. The second question - how are the principles of media literacy education being integrated? — can be dealt with by comparing these characteristics with some of the basic goals of media literacy education discussed earlier.

With regard to content, instructors seem to take an approach aligned with Potter's (2004) conception, oriented primarily toward the transmission of knowledge structures. Most instructors reported that they cover media history, ethics, industries, literacy and effects in their courses in addition to other areas. They reported using a variety of assessment tools such as papers, essay tests, quizzes and in-class exercises. On average, instructors reported lecturing for about half of class time, with discussion making up a quarter, and the remainder being filled by watching/reading media or producing media. Several instructors reported that lecturing is the least ideal way to engage students, but for many instructors it seems to be a necessary evil due to class size. Several instructors reported not paying attention to research related to pedagogy, but others noted their many efforts to engage students through active learning techniques and flipped classroom strategies. Nearly all said they aim to foster engagement with media and civic life through a focus on current events and media consumption. Several noted a focus on the role of media in a democracy and the importance of accessing information from a variety of sources. Diverse perspectives such as those generated by differences in race, gender and politics did not seem to be a problem for those surveyed. Instructors reported that they managed these perspectives by facilitating a respectful, tolerant environment. Challenges faced are probably standard in most educational settings: large classes, limited time and a wide range of student abilities. Together, these findings indicate a broad approach employing a variety of content areas, the use of a variety of assessment tools, and a commitment to active learning and engagement outside of class.

The least commonly cited areas of focus are those most likely to be of interest to the purveyors of critical media literacy: political economy, critical/cultural studies, and comparative media systems (Kellner and Share, 2005; Lewis and Jhally, 1998). If instructors avoid these areas, they may well be missing out on important components of media literacy, specifically, the social, political and economic contexts where media messages live. These are the areas of focus most associated with systems-level analysis, which suggests that educators might be focused more heavily on content than on context. A holistic media education should include equal parts of each of these.

Furthermore, there was little mention of the constructivist or inquiry-oriented approach that Hobbs (2011b) often promotes. For example, when it comes to assessment, few instructors reported using group projects or presentations or blogs. These tools are associated with active learning and engagement, which could mean that instructors are not making the best use of the tools at their disposal to facilitate these important outcomes of media literacy. Instructors also noted that little class time is spent on group work, individual work or presentations. A few reported a heavy focus on creating or producing media, but most did not include this component at all.

Finally, there appears to be no clear method for choosing course content. Instructors decide what to teach based on their experience and on what they deem interesting or important. This points to a lack of clarity among media educators when it comes to developing common goals and outcomes for the introductory media studies course. It could even be a liability with an instructor whose experience is out of date or otherwise misguided. Few would want to shackle educators to a narrow set of rigid requirements, but perhaps greater cohesion throughout media literacy education would help students and instructors alike in achieving desired learning outcomes.

More broadly, it seems that media literacy has remained at the periphery in the fields of journalism and mass communication, which tend to focus more on skills and training, and less on critical analysis. In this journal, for example, a search reveals that media literacy is the focus of only five original research articles. In Journalism and Mass Communication Quarterly, not a single original article centers on media literacy. Future research should continue to explore the role of media literacy in journalism and mass communication programs, particularly when it comes to the opportunity to reach broad segments of campus populations through classes that include and are designed for non-majors. Of course, journalism and communication majors are also in need of media literacy - the kind that includes a focus on political and economic contexts but also leaves plenty of room for self-guided inquiry. 
This is an author-produced, peer-reviewed version of this article. The final, definitive version of this document can be found online at Journalism \& Mass Communication Educator, published by SAGE. Copyright restrictions may apply. doi: 10.1177/1077695815572191

This study is obviously limited by its small sample size, and future research should aim to reach a larger group of instructors. The survey should also be refined and expanded with additional expert input. There is also some lack of parallelism when analyzing introductory courses in journalism and mass communication. Those housed in journalism programs will naturally be oriented differently from those housed in communication departments. Other such nuances are likely to affect survey findings and should be explored and minimized. Despite these shortcomings, this study provides a helpful step in examining and evaluating the introductory media studies course and its incorporation of the important principles of media literacy education.

\section{References}

Aufderheide, P. (1993) Media Literacy: A Report of the National Leadership Conference on Media Literacy. Aspen, CO: Aspen Institute.

Ashley, S., Maksl, A., \& Craft, S. (2013). Developing a news media literacy scale. Journalism \& Mass Communication Educator,68(1), 7-21.

Christ, W. G. (2004). Assessment, media literacy standards, and higher education. American Behavioral Scientist, 48(1), 92-96.

Christ, W. G., \& Hynes, T. (1997). Missions and purposes of journalism and mass communication education. Journalism and Mass Communication Educator, 52(2), 73-100.

Christ, W. G., \& Potter, W. J. (1998). Media literacy, media education, and the academy. Journal of Communication, 48(1), 5.

Dennis, E. E. (2004). Out of sight and out of mind: The media literacy needs of grown-ups. American Behavioral Scientist, 48(2), 202-211.

Ewen, S. (1996). PR!: A social history of spin (1st ed.). New York: Basic Books.

Fleming, J. (2013). Media literacy, news literacy, or news appreciation? A case study of the news literacy program at Stony Brook University. Journalism and Mass Communication Educator 69(2), 146-165.

Hobbs, R. (2010). Digital and Media Literacy: A Plan of Action. Washington D.C.: Aspen Institute.

Hobbs, R. (2011a). What a difference ten years can make: Research possibilities for the future of media literacy education. Journal of Media Literacy Education, 3(1), 29-31.

Hobbs, R. (2011b). “The state of media literacy: A response to Potter.” Journal of Broadcasting and Electronic Media 55(3), 419-430.

Hobbs, R. \& Jensen, A. (2009). "The past, present, and future of media literacy education.” Journal of Media Literacy Education 1(1), 1-11.

Jeong, S., Cho, J. \& Hwang, Y. (2012). Media literacy interventions: A meta-analytic review. Journal of Communication 62(3), 454-472.

Kellner, D., \& Share, J. (2005). Toward critical media literacy: Core concepts, debates, organizations, and policy. Discourse: Studies in the Cultural Politics of Education, 26(3), 369-386.

Lewis, J., \& Jhally, S. (1998). The struggle over media literacy. Journal of Communication, 48(1), 109-120.

Masterman, L. (1997). A rationale for media education. In R. W. Kubey (Ed.), Media literacy in the information age: Current perspectives, information, and behavior (pp. 15-68). New Brunswick, N.J.: Transaction.

McChesney, R. (2004). The problem of the media: U.S. communication politics in the twenty-first century. New York: Monthly Review Press.

Potter, W. J. (2004). Theory of media literacy: a cognitive approach. Thousand Oaks, Calif.: Sage Publications.

Potter, W.J. (2010). “The state of media literacy.” Journal of Broadcasting and Electronic Media 54(4), 675-696.

Shoemaker, P. J., \& Reese, S. D. (2013). Mediating the message in the 21st century: A media sociology perspective (3rd ed.). New York, N.Y.: Routledge.

Silverblatt, A. (2008). Media literacy: keys to interpreting media messages (3rd ed.). Westport, Conn.: Praeger. 
This is an author-produced, peer-reviewed version of this article. The final, definitive version of this document can be found online at Journalism \& Mass Communication Educator, published by SAGE. Copyright restrictions may apply. doi: 10.1177/1077695815572191

\section{Tables}

Table 1. What do you cover in your course? Select all that apply.

\begin{tabular}{|l|c|c|}
\hline Answer & Response & $\%$ \\
\hline Media ethics & 28 & $93 \%$ \\
\hline Media industries & 27 & $90 \%$ \\
\hline Media history & 27 & $90 \%$ \\
\hline Media literacy & 25 & $83 \%$ \\
\hline Media effects & 22 & $73 \%$ \\
\hline Critical thinking & 22 & $73 \%$ \\
\hline Concepts and theories & 19 & $63 \%$ \\
\hline Social science/research & 13 & $43 \%$ \\
\hline Media skills/production & 11 & $37 \%$ \\
\hline Comparative media systems & 9 & $30 \%$ \\
\hline Critical/cultural studies & 6 & $20 \%$ \\
\hline Political economy & 6 & $20 \%$ \\
\hline Other & 6 & $20 \%$ \\
\hline
\end{tabular}

Table 2. If you had to choose one primary focus, what would it be?

\begin{tabular}{|l|c|c|}
\hline Answer & Response & $\%$ \\
\hline Media literacy & 7 & $23 \%$ \\
\hline Media industries & 6 & $20 \%$ \\
\hline Media skills/production & 4 & $13 \%$ \\
\hline Concepts and theories & 3 & $10 \%$ \\
\hline Media effects & 2 & $7 \%$ \\
\hline Critical/cultural studies & 2 & $7 \%$ \\
\hline Media history & 2 & $7 \%$ \\
\hline Other & 2 & $7 \%$ \\
\hline Media ethics & 1 & $3 \%$ \\
\hline Comparative media systems & 1 & $3 \%$ \\
\hline Social science/research & 0 & $0 \%$ \\
\hline Political economy & 0 & $0 \%$ \\
\hline Critical thinking & 0 & $0 \%$ \\
\hline
\end{tabular}

Table 3. What assessment tools do you use? Select all that apply.

\begin{tabular}{|l|c|c|}
\hline Answer & Response & $\%$ \\
\hline Papers & 20 & $67 \%$ \\
\hline Quizzes & 19 & $63 \%$ \\
\hline In-class exercises & 17 & $57 \%$ \\
\hline Essay tests & 16 & $53 \%$ \\
\hline Individual projects or presentations & 14 & $47 \%$ \\
\hline Standardized tests & 12 & $40 \%$ \\
\hline Group projects or presentations & 7 & $23 \%$ \\
\hline Other & 6 & $20 \%$ \\
\hline Blogs & 4 & $13 \%$ \\
\hline
\end{tabular}


This is an author-produced, peer-reviewed version of this article. The final, definitive version of this document can be found online at Journalism \& Mass Communication Educator, published by SAGE. Copyright restrictions may apply. doi: 10.1177/1077695815572191

Table 4. How do you spend class time in a typical week?

\begin{tabular}{|l|r|r|c|c|}
\hline Answer & Min Value & Max Value & Average Value & $\begin{array}{c}\text { Standard } \\
\text { Deviation }\end{array}$ \\
\hline Lecture & 10.00 & 96.00 & 51.88 & 21.50 \\
\hline Discussion & 0.00 & 50.00 & 21.79 & 13.95 \\
\hline $\begin{array}{l}\text { Watching/reading } \\
\text { media }\end{array}$ & 0.00 & 37.00 & 8.29 & 9.89 \\
\hline Group work & 0.00 & 33.00 & 5.71 & 9.13 \\
\hline $\begin{array}{l}\text { Creating/producing } \\
\text { media }\end{array}$ & 0.00 & 50.00 & 5.08 & 13.66 \\
\hline Individual work & 0.00 & 35.00 & 4.71 & 9.22 \\
\hline Presentations & 0.00 & 20.00 & 2.25 & 5.42 \\
\hline Other & 0.00 & 4.00 & 0.29 & 1.00 \\
\hline
\end{tabular}

\section{Appendix A}

\section{Survey Items}

1. What is the name and number of your course?

2. What is the typical enrollment?

3. Is your course required for majors? (Yes, No)

4. Who takes your course? (Majors only, Non-majors only, Mostly majors but it's open to non-majors, A mix of majors and non-majors)

5. Who determines the content of the course? (Just me, Me with others, Others without me)

6. How many years have you taught this course?

7. What is the author and title of your primary text (e.g., Campbell, Media and Culture)? If you do not use a primary text, briefly describe your reading assignments.

8. What do you cover in your course? Select all that apply. (Media effects, Media industries, Critical/cultural studies, Social science/research, Political economy, Concepts and theories, Critical thinking, Media literacy, Media skills/production, Media history, Media ethics, Comparative media systems, Other)

9. If you had to choose one primary focus, what would it be? (Same options as 8)

10. What assessment tools do you use? Select all that apply. (Standardized tests, Essay tests, Quizzes, Papers, Blogs, In-class exercises, Group projects or presentations, Individual projects or presentations, Other)

11. How do you spend class time in a typical week? Apply a percentage for each item. (Lecture, Discussion, Individual work, Group work, Watching/reading media, Creating/producing media, Presentations, Other)

Open-ended questions:

12. How do you decide what to cover in your course?

13. How does research related to pedagogy influence your teaching?

14. Does your approach encourage engagement with media and civic life? If so, how?

15. How do you attempt to manage diverse perspectives in the classroom (race, class, gender, political views, etc.)?

16. What obstacles do you face in achieving your learning goals in this course?

17. Anything else you'd like to say about your course? 